\title{
Improvement in tropospheric moisture retrievals from VIIRS through the use of infrared absorption bands constructed from VIIRS and CrIS data fusion
}

\author{
E. Eva Borbas ${ }^{1}$, Elisabeth Weisz ${ }^{1}$, Chris Moeller ${ }^{1}$, W. Paul Menzel ${ }^{1}$, and Bryan A. Baum ${ }^{2}$ \\ ${ }^{1}$ Cooperative Institute for Meteorological Satellite Studies, University of Wisconsin-Madison, Madison, WI, USA \\ ${ }^{2}$ Science and Technology Corporation, Madison, WI, USA
}

Correspondence: E. Eva Borbas (eva.borbas@ssec.wisc.edu)

Received: 22 June 2020 - Discussion started: 8 July 2020

Revised: 23 October 2020 - Accepted: 7 December 2020 - Published: 15 February 2021

\begin{abstract}
An operational data product available for both the Suomi National Polar-orbiting Partnership (S-NPP) and National Oceanic and Atmospheric Administration-20 (NOAA20) platforms provides high-spatial-resolution infrared (IR) absorption band radiances for Visible Infrared Imaging Radiometer Suite (VIIRS) based on a VIIRS and Crosstrack Infrared Sounder (CrIS) data fusion method. This study investigates the use of these IR radiances, centered at 4.5, 6.7, 7.3, 9.7, 13.3, 13.6, 13.9, and $14.2 \mu \mathrm{m}$, to construct atmospheric moisture products (e.g., total precipitable water and upper tropospheric humidity) and to evaluate their accuracy. Total precipitable water (TPW) and upper tropospheric humidity (UTH) retrieved from hyperspectral sounder CrIS measurements are provided at the associated VIIRS sensor's high spatial resolution $(750 \mathrm{~m})$ and are compared subsequently to collocated operational Aqua Moderate Resolution Imaging Spectroradiometer (MODIS) and S-NPP VIIRS moisture products. This study suggests that the use of VIIRS IR absorption band radiances will provide continuity with Aqua MODIS moisture products.
\end{abstract}

\section{Introduction}

Retrieval of atmospheric water vapor properties from the Visible Infrared Imaging Radiometer Suite (VIIRS) satellite sensor on the Suomi National Polar-orbiting Partnership (S-NPP) and the National Oceanic and Atmospheric Administration-20 (NOAA-20) platforms is challenging due to the absence of infrared (IR) water vapor absorption bands.
Fortunately, measurements in the missing spectral region are available on the Crosstrack Infrared Sounder (CrIS), a hyperspectral IR sensor also on the same platforms. Spectral measurements in these IR absorption bands can be constructed for VIIRS through fusion of the imager and sounder data. Weisz et al. (2017) demonstrated a fusion method to construct IR water vapor and carbon dioxide absorption band radiances for VIIRS at $750 \mathrm{~m}$ spatial resolution. With the addition of the missing spectral bands to VIIRS on S-NPP, this study evaluates total column precipitable water vapor (TPW) and upper tropospheric humidity (UTH) in clear skies through comparison to the Moderate Resolution Imaging Spectroradiometer (MODIS) MYD07 (Borbas et al., 2017) and MYD08 (Platnick et al., 2017) Collection 6.1 and version 1.0 VIIRS (Borbas et al., 2019a-d) atmospheric products. The MYD07 is a level-2 swath product that provides temperature and water vapor profiles at $5 \mathrm{~km}$ spatial resolution, while the MYD08 provides water vapor on a daily, $8 \mathrm{~d}$ and monthly global grid at $1^{\circ} \times 1^{\circ}$ resolution. Through comparison to the MYD07/MYD08 products, we will demonstrate that the VIIRS water vapor product shows better agreement when these constructed band radiances are included, with the major improvement being found in the tropics.

While VIIRS has a wide scanning swath, high horizontal resolution, a nearly constant pixel size across the scan, and a day/night band (DNB), its spectral complement lacks thermal infrared (IR) absorption bands necessary to accurately retrieve tropospheric moisture content as well as cloud properties that rely on those spectral measurements. In particular for moisture retrievals, VIIRS does not take measurements in the broad $6.7 \mu \mathrm{m}$ water vapor band that are measured by 
the MODIS (Seemann et al., 2003). Fortunately, the missing IR spectral bands can be gleaned from measurements on the companion hyperspectral CrIS sensor on the same platform.

Here, we denote the instantaneous field of regard as field of view (FOV) for the sounder and pixel for the imager exclusively to minimize confusion between the two sensors. To achieve TPW and UTH at imager pixel resolution, this study employs the innovative data fusion approach of Weisz et al. (2017) that constructs MODIS-like water vapor and $\mathrm{CO}_{2}$ sensitive radiances directly at the imager resolution through use of collocated VIIRS and CrIS radiances. In this study, the data fusion method provides MODIS-like IR absorption band radiances at the VIIRS M-band spatial resolution $(750 \mathrm{~m})$. The VIIRS+CrIS fusion radiances are available for the entire record of both the S-NPP and NOAA-20 platforms (Baum et al., 2019a).

The availability of these IR-band radiances for VIIRS at $750 \mathrm{~m}$ pixel resolution makes it possible to retrieve a cloud mask and moisture properties using algorithms developed and tested using the full MODIS spectral band suite (Borbas et al., 2011). The goal of this study is to determine the impact of supplementing VIIRS with imager-resolution VIIRS+CrIS fusion bands on retrieving TPW and UTH and establish the feasibility of extending the MODIS TPW and UTH into the future with those derived from VIIRS+CrIS fusion. The continuation of such a high-spatial-resolution product will maintain the benefit to observe high-spatialscale weather phenomena, detect an urban heat island $(\mathrm{Hu}$ and Brunsell, 2015), or determine atmospheric correction for high-spatial-resolution remote sensing products, such as the MODIS land surface temperature products (Proud et al., 2010; Hulley et al., 2017; Wan, 2010).

This work is a clear-sky moisture companion to the cloud parameter fusion paper of $\mathrm{Li}$ et al. (2020), wherein they reported on the improvement in VIIRS detection and characterization of clouds through the use of additional infrared fusion radiances.

This paper is organized as follows: Sect. 2 discusses data and fusion method, Sect. 3 summarizes the moisture retrieval method and presents results, and a summary of the findings is provided in Sect. 4.

\section{Data and methodology}

The VIIRS sensor is a 22-band scanning radiometer that is currently flying on the NASA S-NPP and the NOAA-20 platforms. VIIRS has 16 bands scanning a $3000 \mathrm{~km}$ swath at $750 \mathrm{~m}$ resolution (medium resolution, or $\mathrm{M}$ ), five bands at $375 \mathrm{~m}$ resolution (imaging, or I), and a day/night band. For this investigation, the focus is on using the bands at $M$ resolution. The data used in this study include the standard level-1B VIIRS data for both the S-NPP and NOAA20 platforms made available by the Atmosphere Science Investigator-led Processing System (A-SIPS) located at the
University of Wisconsin - Madison Space Science Engineering Center (SSEC).

CrIS is a Fourier transform spectrometer with 1305 spectral channels in normal spectral resolution (NSR) and 2211 channels in full spectral resolution (FSR) over three wavelength ranges: longwave infrared (LWIR) (9.14 to $15.38 \mu \mathrm{m}$ ); midwave-infrared (MWIR) (5.71 to $8.26 \mu \mathrm{m}$ ); and shortwave infrared (SWIR) (3.92 to $4.64 \mu \mathrm{m})$. CrIS scans a $2200 \mathrm{~km}$ swath width $\left( \pm 50^{\circ}\right)$, with 30 Earth-scene views. Each view consists of nine FOVs from a $3 \times 3$ array that have a nadir spatial resolution of approximately $14 \mathrm{~km}$.

The fusion method requires an accurate collocation between the high-spatial-resolution imager data (with pixels at $750 \mathrm{~m}$ ) and the lower-spatial-resolution sounder data (with FOVs at about $14 \mathrm{~km}$ ). The fusion method described in Weisz et al. (2017) consists of two steps for each imager pixel: (a) search nearby neighbors to find the five FOVs that best match the split-window (i.e., 11 and $12 \mu \mathrm{m}$ ) imager pixel radiances averaged over the FOV to an individual pixel's splitwindow measurements - this is accomplished using a $k-d$ (or multi-dimensional) tree search algorithm (Bentley, 1975) on both high-spatial-resolution (M-band 11 and $12 \mu \mathrm{m}$ data) and low-spatial-resolution (M-band 11 and $12 \mu \mathrm{m}$ data averaged over the CrIS FOV) imager radiances. (b) Convolve the high-spectral-sounder radiances (at low spatial resolution) to the desired IR broadband, then average the convolved sounder radiances associated with the selected five nearest neighbors to construct the desired spectral band for each imager pixel. Spectral radiance convolution refers to the process of converting high-spectral-resolution (narrowband) to broadband radiance measurements by applying a spectral response function (SRF) of a given broadband. Here, SRFs associated with the spectral bands of the MODIS sensor on the NASA Earth Observation System (EOS) Aqua platform are applied to CrIS measurements. The VIIRS+CrIS fusion IR absorption band radiances are available for the entire records of S-NPP and NOAA-20 at the Level-1 and Atmosphere Archive and Distribution System (LAADS) Distributed Active Archive Center (DAAC) at the NASA Goddard Space Flight Center (Baum et al., 2019ab).

VIIRS+CrIS fusion radiances alongside observed radiances for MODIS bands $25(4.5 \mu \mathrm{m}), 27(6.7 \mu \mathrm{m})$, and 35 $(13.9 \mu \mathrm{m})$, repeated from Weisz et al. (2017), are shown in Fig. 1. The fusion results for band 27 show more inaccuracies, because $\mathrm{H}_{2} \mathrm{O}$-sensitive spectral bands sense different tropospheric regions than split-window spectral bands. Also, small-scale and narrow spatial features in moisture (e.g., dry slots and cloud edges), which are not captured by the sounder due to its large spatial resolution, are more problematic for the fusion process. Furthermore, the results at the edge of the imager granule (i.e., outside the sounder swath) should be used with caution since they do not account for "limb darkening" and hence tend to be less accurate. Results shown in Fig. 1 for the VIIRS+CrIS fusion radiances compared well 
(a)
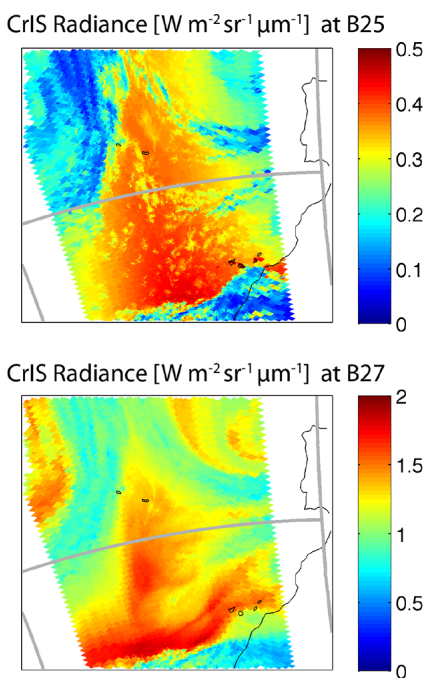

CrIS Radiance $\left[\mathrm{W} \mathrm{m}^{-2} \mathrm{sr}^{-1} \mu \mathrm{m}^{-1}\right]$ at B35

(c)

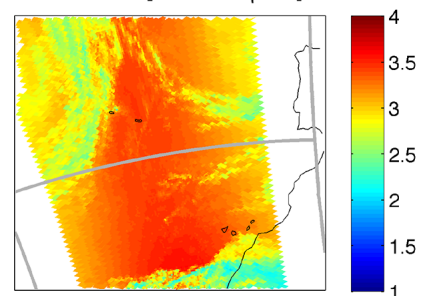

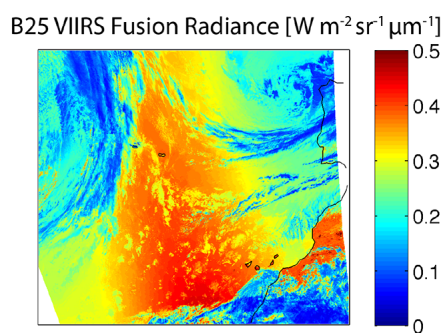

B27 VIIRS Fusion Radiance [W $\left.\mathrm{m}^{-2} \mathrm{sr}^{-1} \mathrm{~mm}^{-1}\right]$

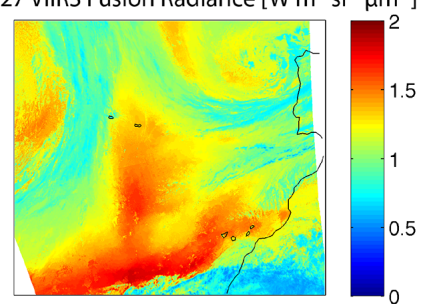

B35 VIIRS Fusion Radiance [W $\mathrm{m}^{-2} \mathrm{sr}^{-1} \mathrm{\mu m}^{-1}$ ]

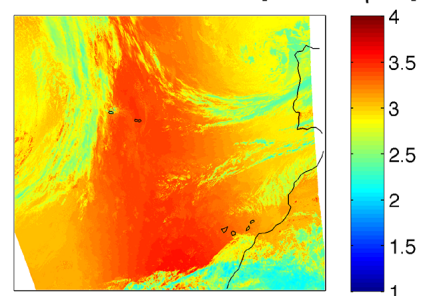

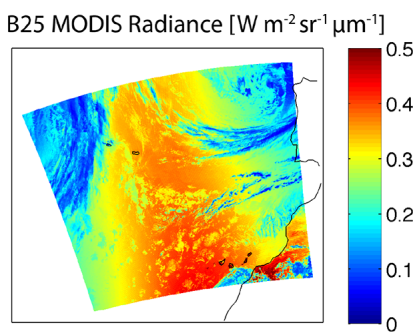

B27 MODIS Radiance [W m $\left.{ }^{-2} \mathrm{sr}^{-1} \mathrm{um}^{-1}\right]$

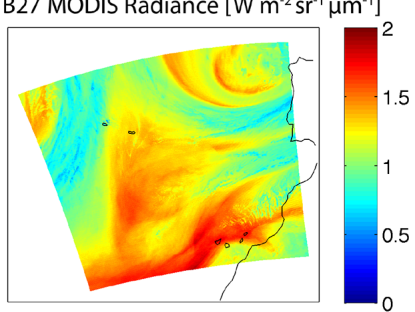

B35 MODIS Radiance [ $\left.\mathrm{W} \mathrm{m}^{-2} \mathrm{sr}^{-1} \mu \mathrm{m}^{-1}\right]$

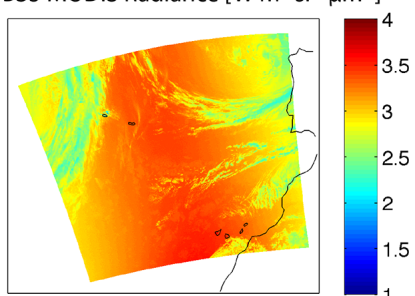

Figure 1. CrIS sounder radiance (left), newly constructed fusion radiance (middle), and the observed MODIS radiance differences (right) for MODIS bands $25(4.5 \mu \mathrm{m}), 27(6.7 \mu \mathrm{m})$, and $35(13.9 \mu \mathrm{m})$ in rows (a, b, c), respectively, for one granule at 14:36 UTC on 17 April 2015 . This is shown in Fig. 8 in Weisz et al. (2017).

in a qualitative sense with the observed MODIS radiances, even in the more challenging water vapor band.

To assess the viability of the moisture products to provide continuity with similar products from MODIS, we perform a comparison with collocated measurements (i.e., matchups) with Aqua MODIS. For this study, the collocation process requires the VIIRS $750 \mathrm{~m}$ pixel to be fully contained within the MODIS $1 \mathrm{~km}$ pixel; the scene must be high confidence clear (as identified by the MODIS cloud mask MYD35); and the scan angles for the matching pair must be less than $50^{\circ}$ so that it is within the swath of the CrIS sensor. Figure 2 shows the results of tens of thousands of instances of collocated MODIS and VIIRS+CrIS fusion radiances that are converted to brightness temperatures (BTs) in two water vapor and four carbon dioxide bands for the month of April 2018. It can be seen that the mean clear-sky brightness temperature differences (BTDs) between VIIRS+CrIS fusion and original MODIS data are less than $0.5 \mathrm{~K}$ for MODIS $\mathrm{H}_{2} \mathrm{O}$ bands 27 and $28(6.7$ and $7.3 \mu \mathrm{m})$ and MODIS $\mathrm{CO}_{2}$ bands 33 to 36 $(13.3,13.6,13.9$, and $14.2 \mu \mathrm{m})$ for $11 \mu \mathrm{m}$ BTs ranging from 200 to $280 \mathrm{~K}$. Root mean square scatter (not shown) about these mean values is found to be $1.1 \mathrm{~K}$ for the $\mathrm{H}_{2} \mathrm{O}$ bands and $0.5 \mathrm{~K}$ for the $\mathrm{CO}_{2}$ bands. MODIS radiance comparisons with respect to Infrared Atmospheric Sounding Interferom- eter (IASI) over 6 years found that the water vapor bands showed scatter up to $1.0 \mathrm{~K}$ in the $\mathrm{H}_{2} \mathrm{O}$ bands and $0.5 \mathrm{~K}$ in the $\mathrm{CO}_{2}$ bands (Moeller et al., 2014). The fusion comparison results are similar. Thus, it can be summarized that an order of magnitude spatial resolution (from $14 \mathrm{~km}$ to $750 \mathrm{~m}$ ) has been added at the cost of introducing measurement offsets of 0.25 to $0.5 \mathrm{~K}$ and noise of 0.5 to $1.0 \mathrm{~K}$. Results for all 12 months in 2018 (not shown) are similar; in fact, results for the entire S-NPP archive show comparably positive fusion results.

\section{TPW and UTH algorithm and results}

Our retrieval of TPW and UTH from selected IR measurements adopts a statistical regression algorithm (Seemann et al., 2003, 2008; Li et al., 2000; Smith and Woolf, 1988; Hayden, 1988) performed using clear-sky radiances (and BTs) measured over land and ocean for both day and night. The regression is developed with the SeeBor training database (Borbas et al., 2005) that consists of over 15000 atmospheric profiles globally and seasonally well distributed. The water vapor retrieval algorithm has two parts: first, the regression coefficients are calculated using radiative transfer calculations, and then the regression retrieval is performed. The radiative transfer calculation of the MODIS-like radiances of 
(a)

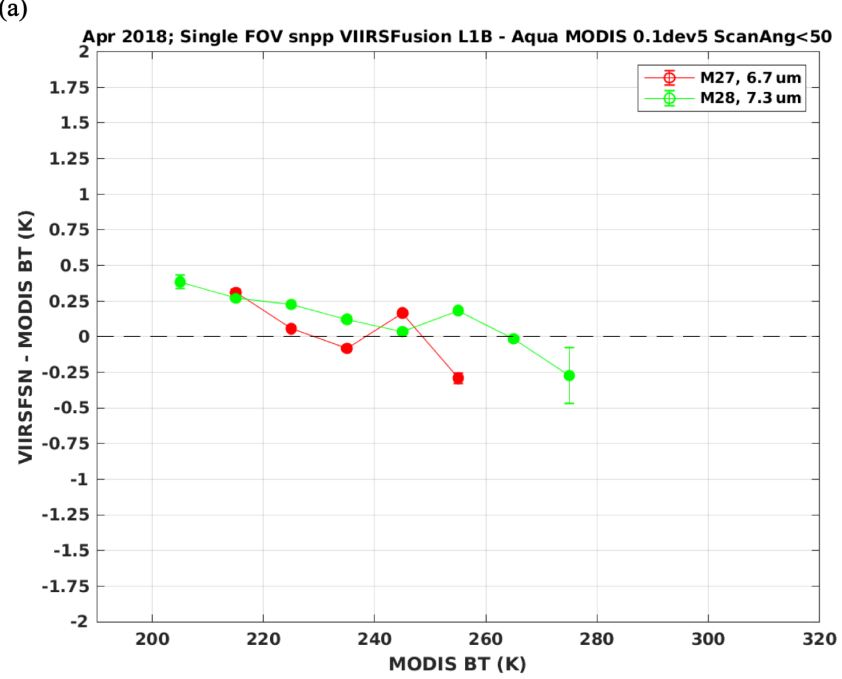

(b)

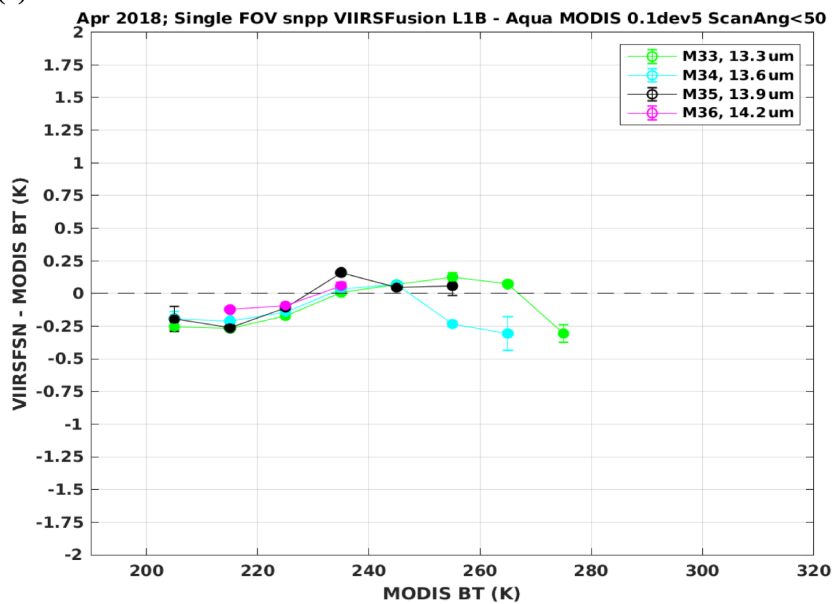

Figure 2. Comparison of collocated MODIS and VIIRS+CrIS fusion water vapor (a) and carbon dioxide (b) band brightness temperatures for the month of April 2018. Each data point in the plots (within a $10^{\circ}$ brightness temperature bin) represents more than 10000 collocations.

bands $25,27,28$, and $30-36$ is performed using the forward model called Radiative Transfer for TOVS (RTTOV) version 12 (Saunders et al., 2018). The regression relationships between the calculated BTs and retrieved moisture products are generated for four (and three) different BT zones over land and ocean, respectively, and 60 sensor zenith angles from nadir to $60^{\circ}$. The only other ancillary information required is the surface pressure, which is provided by National Centers for Environmental Prediction (NCEP) reanalysis data (Saha et al., 2010). TPW and UTH are determined for clear-sky radiances measured by VIIRS and calculated from VIIRS+CrIS fusion. The retrieval approach is similar to that adopted for MODIS. There is a strong reliance on radiances from 6.7, 11, and $12 \mu \mathrm{m}$. The operational VIIRS cloud mask (called CLDMSK_L2_VIIRS_SNPP.001; Ackerman et al., 2019) is applied to VIIRS to characterize the probability of cloud cover.

Figure 3 shows CrIS TPW and UTH at the sounder FOV resolution; they outline the tropospheric moisture gradients at coarse $(\sim 14 \mathrm{~km})$ resolution for clear and partly cloudy skies. The soundings are obtained using the dual regression method (Smith et al., 2012; Weisz et al., 2013), which is a computationally fast, physically based method that retrieves profiles as well as surface and cloud properties from high-spectral-resolution radiances measured in both clearand cloudy-sky conditions at single-FOV resolution. TPW represents the total column integration of the moisture profile, while UTH is the integration from $400 \mathrm{hPa}$ to the top of the atmosphere. Also shown are the regression retrieval results for the VIIRS+CrIS fusion spectral band radiances (created using the MODIS-like IR spectral response functions) at higher spatial resolution $(\sim 750 \mathrm{~m})$ in pixels deemed to be clear in the VIIRS cloud mask. They display more refined features and improve the coverage but show higher values of TPW off the coast of Baja and miss some of the UTH features in Wyoming and Colorado that were suggested in the CrIS soundings. While the results are derived from two independent algorithms, this example illustrates a challenge for the VIIRS split-window search for nearby FOVs; the search will rely primarily on low-level temperature and moisture features and less on mid-level to upper-level moisture gradients.

\subsection{TPW results}

A $1 \mathrm{~d}$ evaluation of the VIIRS+CrIS TPW fusion product is shown in Fig. 4. Global comparisons for 9 April 2018 are made for the TPW field derived from (1) VIIRS+CrIS fusion radiances using the operational MODIS L2 algorithm, (2) MODIS operational Collection 6.1 MYD08 (MYD08_D3.061, Platnick et al., 2017), (3) VIIRS-only (Borbas et al., 2019d), and (4) the VIIRS+NUCAPS (Borbas et al., 2019d) operational products developed under a NASAfunded project.

The VIIRS-only product is a statistical regression based on the split-window radiances; it suffers from no information about mid- to upper tropospheric moisture. In the VIIRS+NUCAPS operational products, VIIRS IR measurements are merged with CrIS and Advance Technology Microwave Sounder (ATMS) water vapor soundings in an earlier attempt to continue the depiction of global moisture at high spatial resolution started with MODIS. A clear-sky regression relationship has been established between TPW and VIIRS IR window BTs and NOAA Unique Combined Atmospheric Processing System (NUCAPS) water vapor soundings calculated from a global training radiosonde-based profile dataset. NUCAPS TPW was added in clear and partly cloudy regions to enhance the TPW depiction and to extend the coverage. The CrIS and ATMS sounding products are provided by NUCAPS (Gambacorta, 2013). The main 
(a)

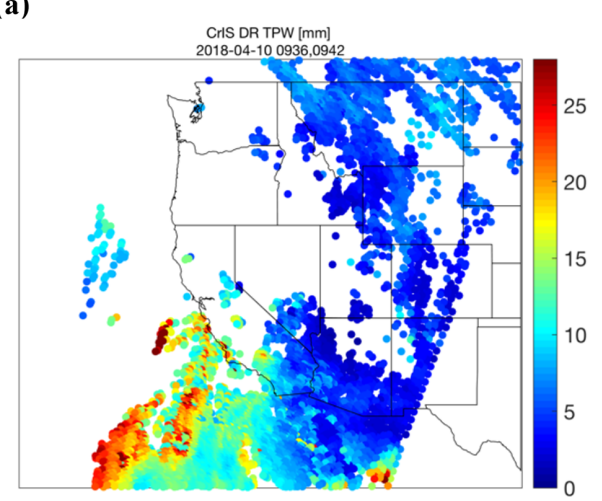

(c)

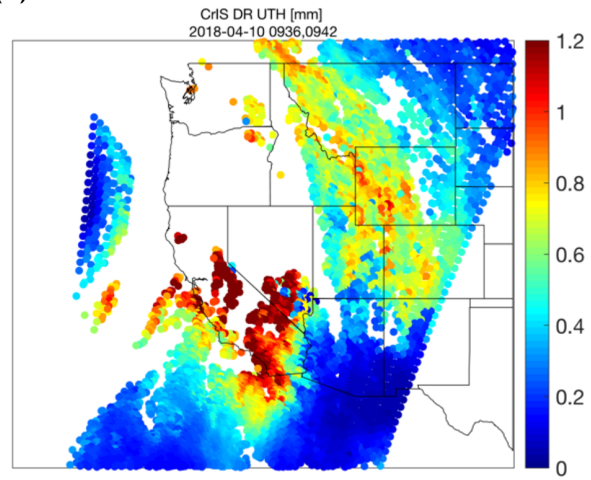

(b)

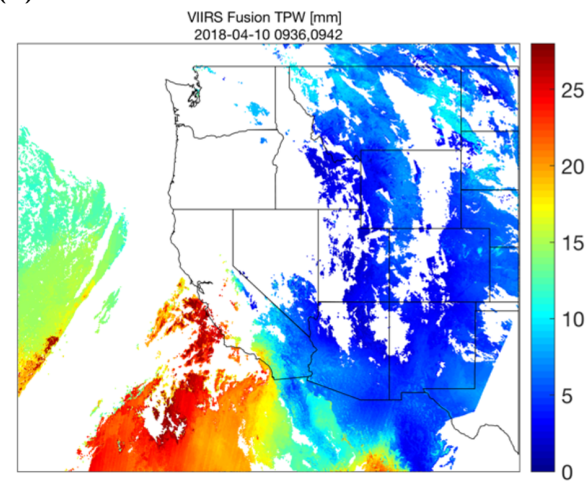

(d)

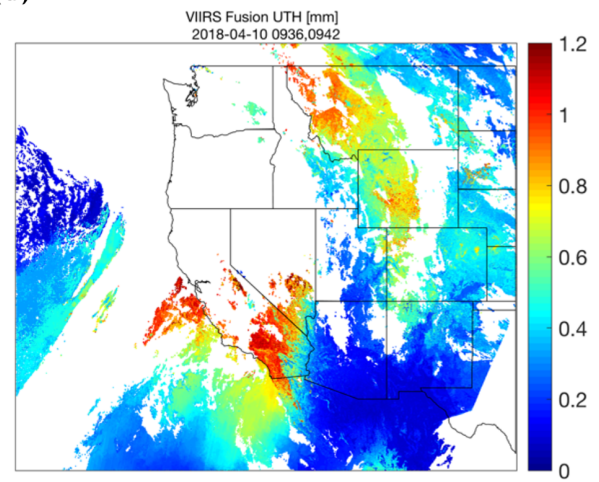

Figure 3. TPW (a, b) and UTH (c, d) (both in mm) are shown for CrIS DR retrievals at sounder resolution (a, c) along with regression retrievals derived from VIIRS+CrIS fusion radiances at imager resolution (b, d) for 10 April 2018, at 09:36 and 09:42 UTC (CrIS granule start times).

idea of merging these products is to capitalize on the unique strengths of each product's spatial and spectral characteristics in the infrared region. VIIRS, with solely the IR window channels, only gives some indication of low-level moisture (which constitutes much of the total column amount), and we complement this with CrIS+ATMS sounding column moisture retrievals. This VIIRS+NUCAPS algorithm follows the approach used for MODIS. A clear-sky regression relationship is established between TPW (predictand) and VIIRS IR window brightness temperatures (BTs), and the NUCAPS TPW soundings (predictors) calculated from a global training radiosonde-based profile dataset. To help differentiate surface emission and atmospheric moisture absorption and to get better surface characteristics in the forward model calculation, surface emissivity for the VIIRS channels used in the regression method has been assigned for each profile in the training dataset from the University of Wisconsin high-spatial-resolution surface emissivity database (Borbas et al., 2018). First, the VIIRS-only clear-sky TPW is generated and stored; subsequently, the VIIRS+NUCAPS TPW is calculated in clear-sky conditions. Gaps in the VIIRS+NUCAPS TPW field are filled with adjusted VIIRSonly or adjusted NUCAPS-only products. In this paper, we use both the VIIRS-only and VIIRS+NUCAPS total column properties for evaluation.

Figure 4 shows that the global mean of the TPW derived from the VIIRS+CrIS fusion radiances is found to be $0.3 \mathrm{~mm}$ too low, with a scatter of $3.3 \mathrm{~mm}$ when compared to the MYD08 TPW. The VIIRS-only operational TPWs are $1.3 \mathrm{~mm}$ higher than the MYD08 TPW with a scatter of $4.0 \mathrm{~mm}$; much of the VIIRS overestimation of TPW occurs in the tropical oceans. VIIRS+NUCAPS TPWs also compare well with the same $0.3 \mathrm{~mm}$ bias but with a slightly higher $3.5 \mathrm{~mm}$ scatter in the comparison to MYD08 TPW. However, it does not capture the maxima in the Brazilian rainforest moisture found in the MYD08 TPW. The latitudinal distribution of the differences in Fig. 5 shows good agreement between VIIRS+CrIS fusion and MYD08 and overestimation of VIIRS-only from $40^{\circ} \mathrm{S}$ to $10^{\circ} \mathrm{N}$ latitude. Over the tropics, where the highest moisture levels occur, the VIIRS+CrIS fusion product agrees more closely with the MYD08 than the VIIRS+NUCAPS, which mostly underestimates the water vapor content. For this $1 \mathrm{~d}$ global comparison, providing $\mathrm{H}_{2} \mathrm{O}$ fields from fusion bands can be regarded as a success for bringing VIIRS+CrIS TPW into family with MYD08 TPW with a slightly better agreement than with the 
(a)

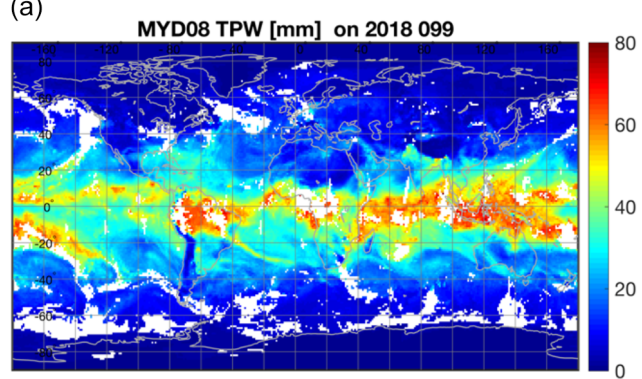

(c)

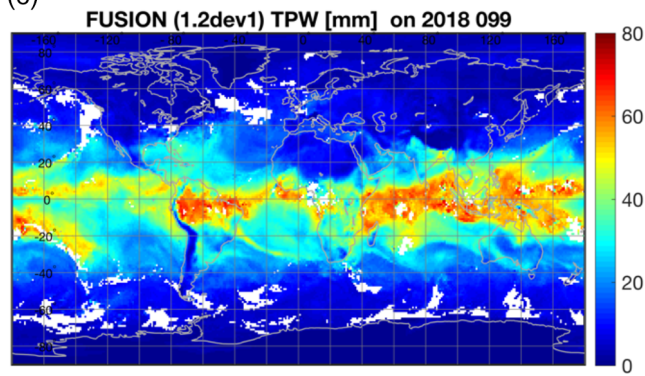

(e)

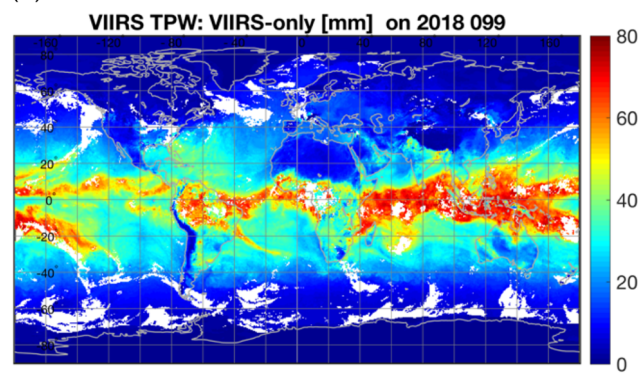

(g)

VIIRS TPW: VIIRS+NUCAPS [mm] on 2018099

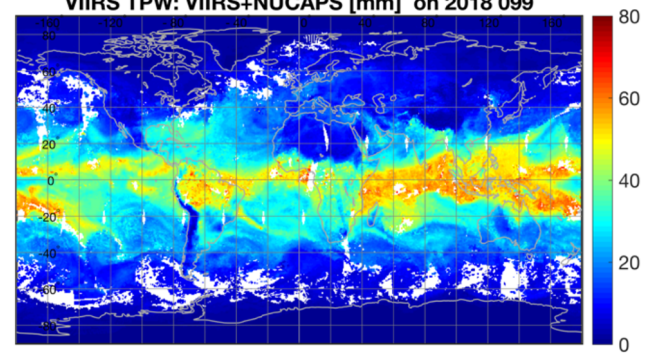

(b) FUSION (1.2dev1) - MODIS TPW [mm] on 2018099

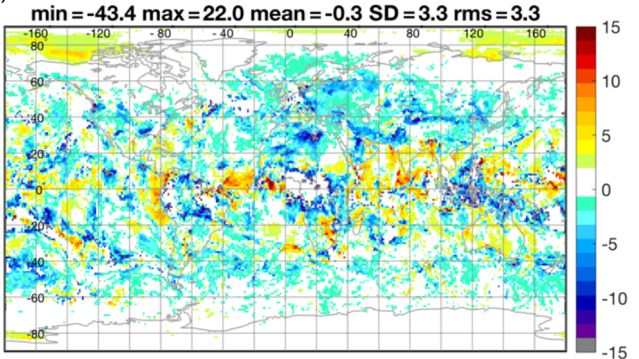

(d) FUSION(1.2dev1) - VIIRS-only TPW [mm] on 2018099

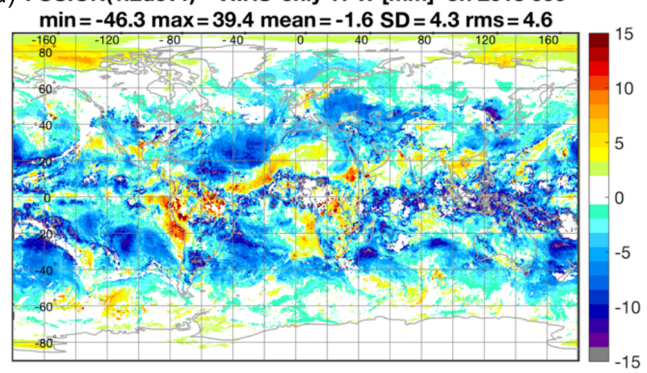

(f)

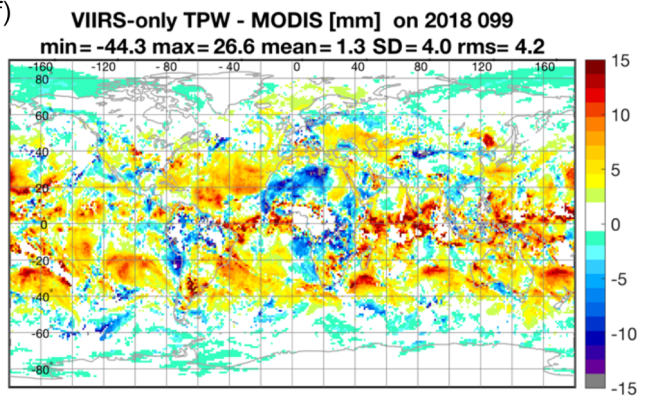

(h) VIIRS+NUCAPS TPW - MODIS [mm] on 2018099

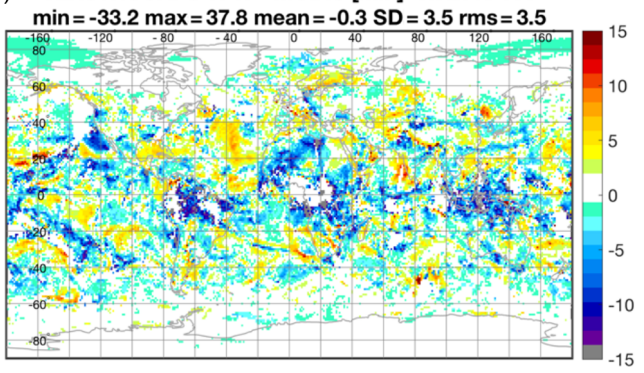

Figure 4. Left panels: geographical distribution of TPW (mm) results derived from the MODIS MYD08_D3 Collection 6.1 (a), VIIRS+CrIS fusion (c), VIIRS-only (e), and the VIIRS+NUCAPS (g) products for 9 April 2018. The right panels show the corresponding difference fields with their statistics, such as the minimum (min), maximum (max), mean, standard deviation (SD), and root mean square (rms) differences; their values are included in the subtitles.

VIIRS+NUCAPS product and additionally providing a significant improvement over the VIIRS-only product.

The $1 \mathrm{~d}$ comparisons are now extended to monthly comparisons. Figure 6 shows zonal scatter plots for the month of April 2017 of VIIRS+CrIS fusion, VIIRS-only, and VIIRS+NUCAPS TPW, each with respect to MYD08. The segmentation is divided into three zones of 60 to $30^{\circ} \mathrm{N}$ (northern midlatitudes), $30^{\circ} \mathrm{N}$ to $30^{\circ} \mathrm{S}$ (tropics), and 30 to $60^{\circ} \mathrm{S}$ latitudes (southern midlatitudes). VIIRS+CrIS fusion TPW shows differences in all three zones in the mean $(-1.16,0.24$, and $-0.49 \mathrm{~mm}$, respectively) and standard deviation $(0.95,1.89$, and $0.66 \mathrm{~mm}$, respectively); the dry bias is greater than $1 \mathrm{~mm}$ in the northern midlatitudes and is pervasive in the eastern US, the northern Atlantic Ocean, through Europe, and continuing to western Russia. Overall good agreement is found in dry (less than 

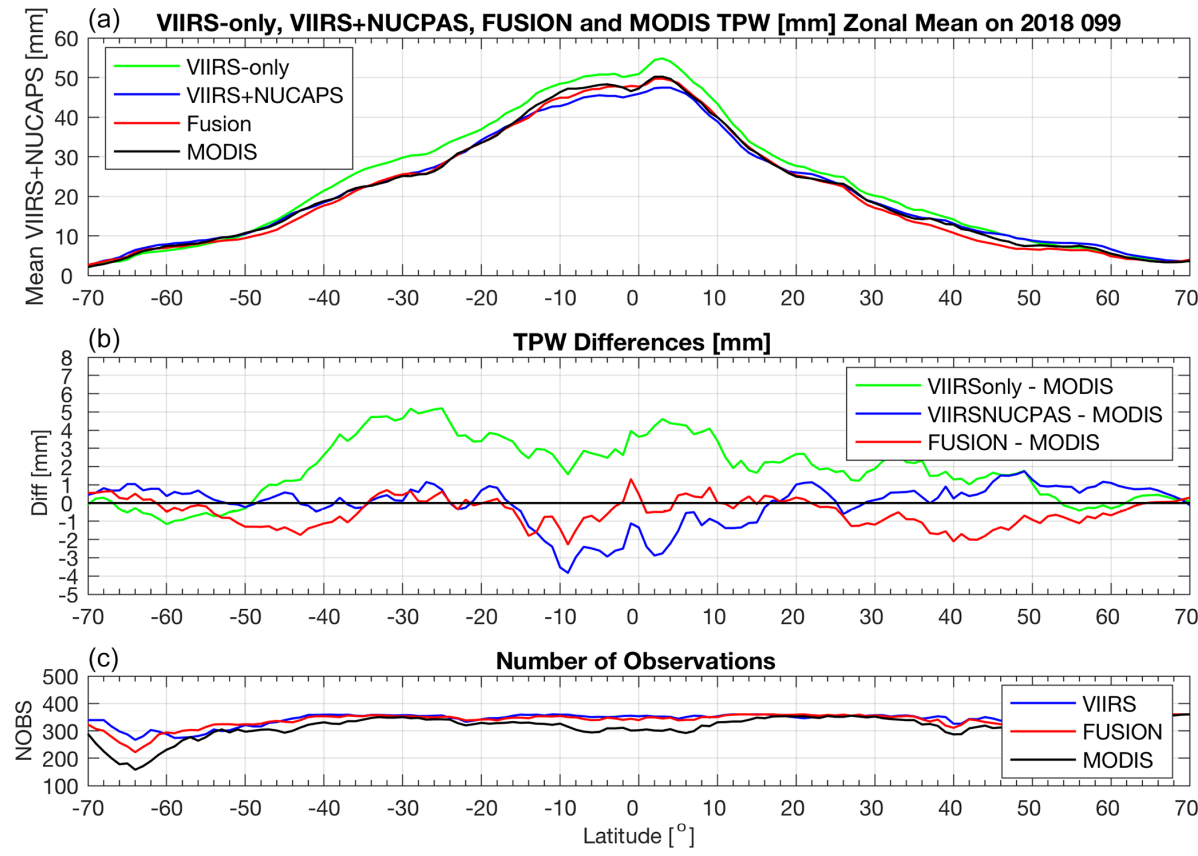

Figure 5. Panel (a) shows the latitudinal distribution of TPW (mm) results for the same days and products as in Fig. 4. Panel (b) illustrates the corresponding differences, while panel (c) shows the number of observations occurring in each $1^{\circ}$ latitude bin.
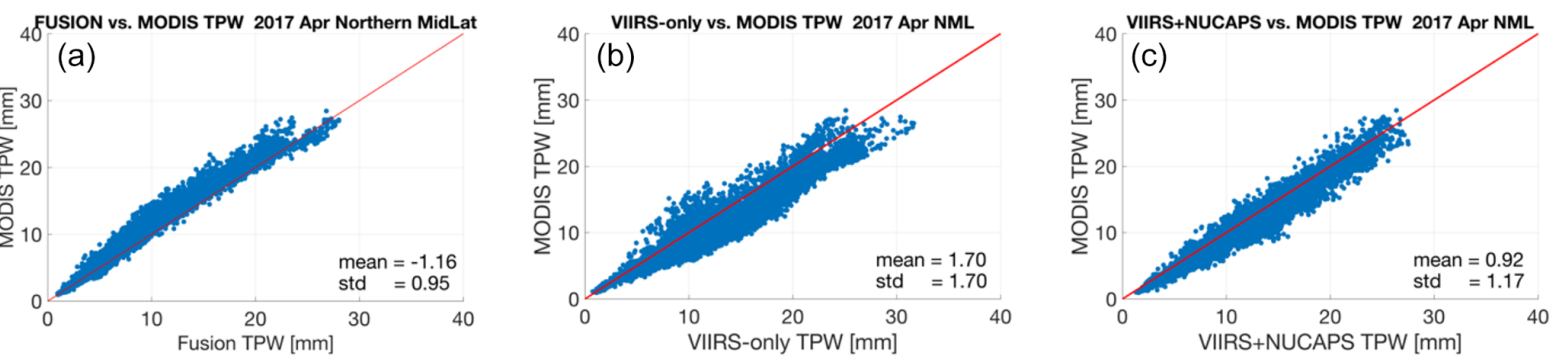

${ }^{80}(\mathrm{~d})$
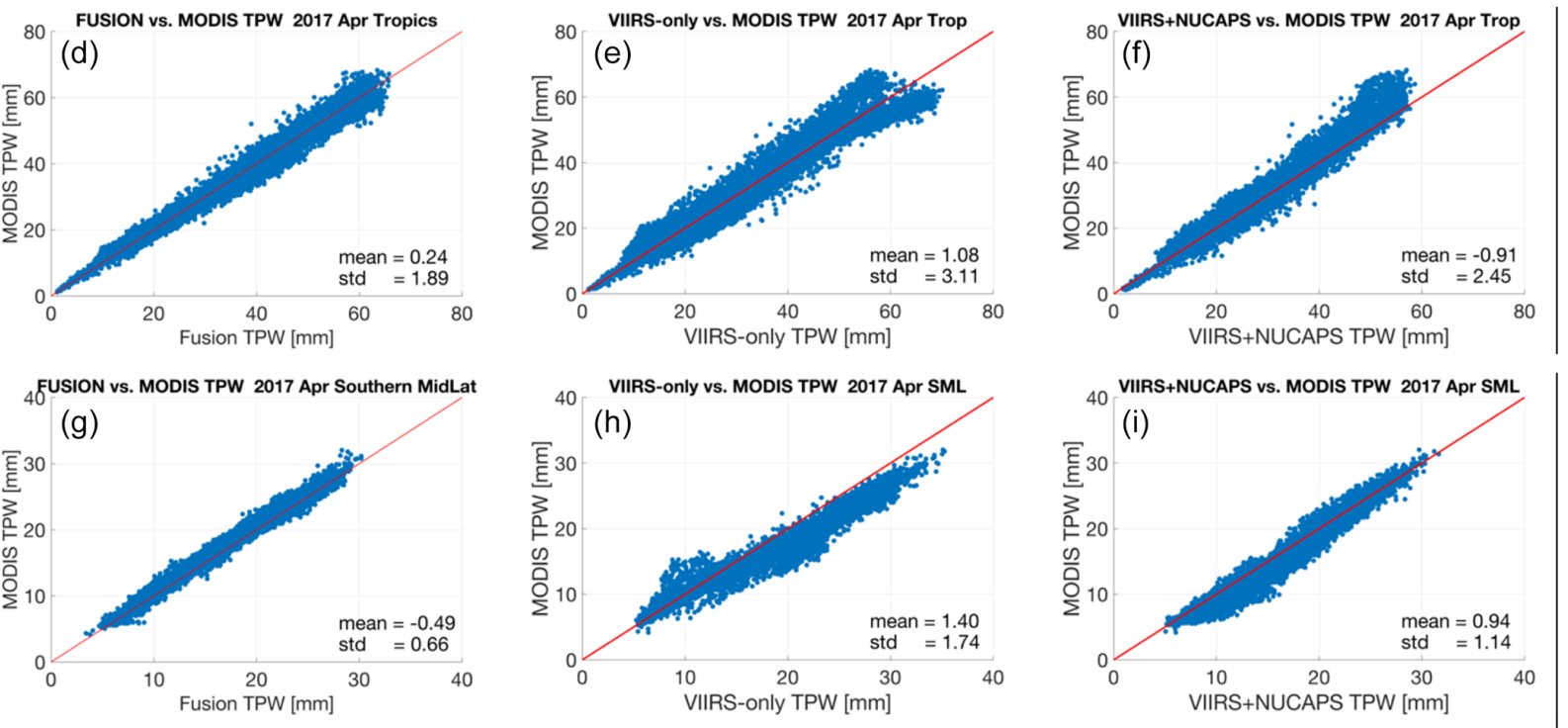

Figure 6. TPW scatter plot of VIIRS+CrIS fusion (a, d, g), VIIRS-only (b, e, h), and VIIRS+NUCAPS (c, f, i) versus MODIS MYD08_M3 Collection 6.1 for northern midlatitudes (NML) between 30 and $60^{\circ} \mathrm{N}(\mathbf{a}, \mathbf{b}, \mathbf{c})$, tropics between $30^{\circ} \mathrm{S}$ and $30^{\circ} \mathrm{N}(\mathbf{d}$, e, f), and southern midlatitudes (SML) between 30 and $60^{\circ} \mathrm{S}(\mathbf{g}, \mathbf{h}, \mathbf{i})$ in April 2017. 
(a)

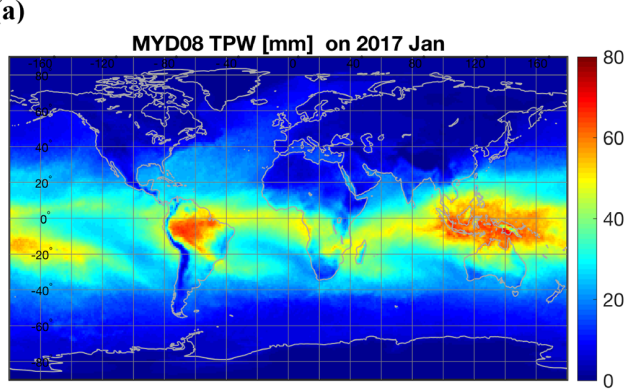

(c)

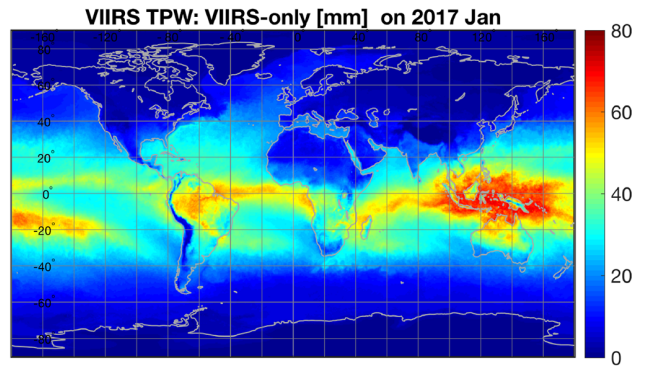

(b)

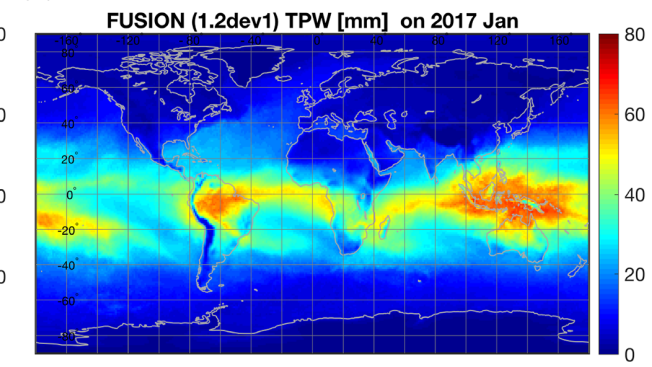

(d)

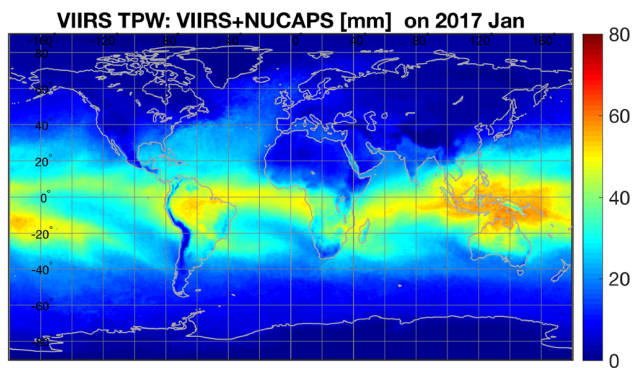

Figure 7. January 2017 geographical distribution of TPW (mm) results derived from the (a) MODIS MYD08_M3 Collection 6.1, (b) VIIRS +CrIS fusion, (c) VIIRS-only, and (d) VIIRS+NUCAPS products.

$5 \mathrm{~mm}$ ) as well as wet (greater than $60 \mathrm{~mm}$ ) atmospheres. Similar comparisons are less favorable for VIIRS-only and VIIRS+NUCAPS, with the exception of northern midlatitudes where VIIRS+NUCAPS shows a smaller absolute bias in the mean of $0.92 \mathrm{~mm}$. The VIIRS+CrIS fusion compares with MODIS TPW within the MODIS product accuracy of determined from CART site comparisons (Borbas et al., 2011, MODIS Atmospheric Products ATBD); thus, VIIRS+CrIS is shown to be a viable source for MODIS moisture product record continuation.

Figures 7 and 8 show the global comparison of monthly differences for January 2017. These results reinforce the $1 \mathrm{~d}$ results, especially with regard to VIIRS+CrIS TPW being the best match of the three VIIRS-derived TPWs with MYD08 TPW; VIIRS+CrIS has the lowest mean difference at $0.2 \mathrm{~mm}$ and standard deviation of $1.4 \mathrm{~mm}$ compared to, respectively, 1.1 and $2.7 \mathrm{~mm}$ for VIIRS alone and 0.3 and $2.0 \mathrm{~mm}$ for VIIRS+NUCAPS. The improvement is most noticeable (see Fig. 8) over the Brazilian rainforest and the ITCZ (Intertropical Convergence Zone).

To extend this analysis to a four-season evaluation, VIIRS+CrIS TPW differences with respect to MYD08 TPW are shown for January, April, July, and October 2017 in Fig. 9. Mean agreement ranges from $0.0 \mathrm{~mm}$ in April to $0.4 \mathrm{~mm}$ in October; the standard deviation is largest in July at $1.8 \mathrm{~mm}$, which is still smaller than the standard deviation of any of the other three VIIRS-derived products in January 2017. Local VIIRS+CrIS overestimations occur over Australian deserts in January and during the Indian monsoon in July; underestimation is found in the Brazilian rainfor- est and the ITCZ in January and the Sahara in July. Overall, VIIRS+CrIS TPW agrees very well with MODIS TPW for all 4 months representing the four seasons.

\subsection{UTH results}

Figure 10 shows the results for the VIIRS+CrIS fusion UTH product. The UTH global images on the top two panels show the spatial distribution of UTH within the $0-3 \mathrm{~mm}$ range. Here, the global mean derived from the VIIRS + CrIS fusion radiances is found to be $0.02 \mathrm{~mm}$ higher with a scatter of $0.14 \mathrm{~mm}$ when compared to the MYD08 UTH. Local differences of $\pm 1 \mathrm{~mm}$ are found in the tropics. The latitudinal distribution of the differences (Fig. 11) shows modest overestimation in the VIIRS+CrIS fusion UTH everywhere with a peak from $10^{\circ} \mathrm{S}$ to the Equator. Note that the operational VIIRS moisture products do not currently include the UTH product but only total column moisture information, since VIIRS has a limited ability to sense the upper tropospheric moisture. Again, in this global comparison for $1 \mathrm{~d}$, use of the $\mathrm{H}_{2} \mathrm{O}$ fusion bands brings VIIRS+CrIS fusion UTH into family with MYD08 UTH. Without the fusion radiances, VIIRS has little or no sensitivity to UTH.

Figure 12 shows the UTH comparison results for 1 month in each season that complement the TPW results in Fig. 9. The mean agreement for VIIRS+CrIS UTH with MODIS UTH ranges from 0.03 to $0.05 \mathrm{~mm}$ and standard deviation from 0.05 to $0.08 \mathrm{~mm}$. The greatest local differences are found with VIIRS+CrIS too wet in the ITCZ in January, too wet in the Brazilian rainforest in April, too dry in the Himalayas, and too wet in India in July, and again too wet in 
(a)

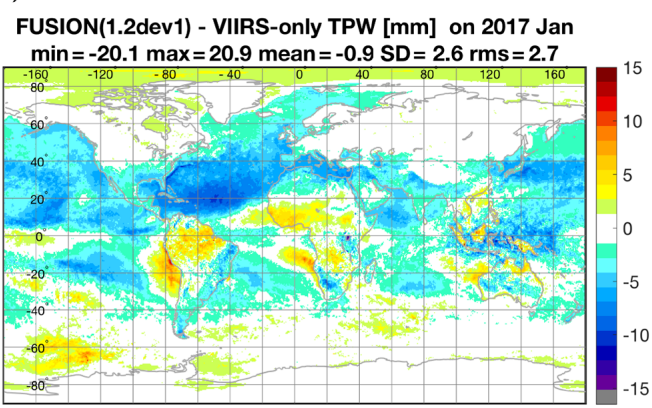

(c)

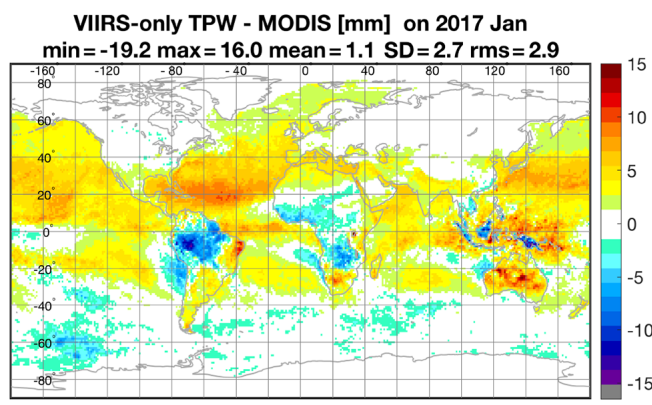

(e)

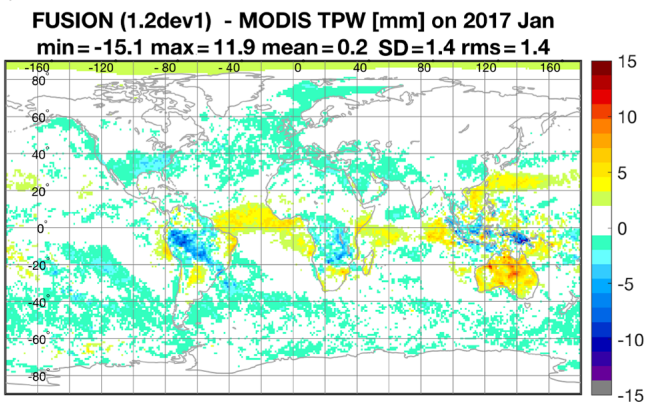

(b)

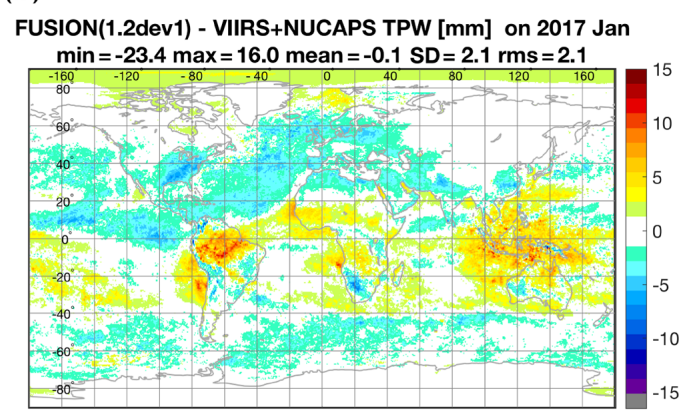

(d)

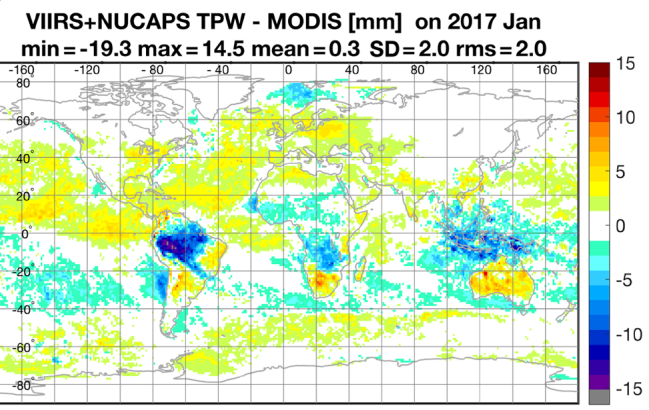

Figure 8. January 2017 TPW (mm) difference fields of VIIRS+CrIS fusion minus VIIRS-only (a), VIIRS+CrIS fusion minus VIIRS+NUCAPS (b), VIIRS-only minus MODIS (c), VIIRS+NUCAPS minus MODIS (d), and VIIRS+CrIS fusion minus MODIS. MODIS refers to MYD08_M3 Collection 6.1 products. Minimum (min), maximum (max), mean, standard deviation (SD), and root mean square (rms) differences are shown in the subtitles.

the ITCZ in October. Overall, the results are typically within $10 \%$ of each other and accurate enough to determine daily and seasonal variability.

\section{Summary and conclusions}

The absence of water vapor and $\mathrm{CO}_{2}$ absorption IR spectral bands on the VIIRS imager on the S-NPP and NOAA20 polar-orbiting platforms limits the capability for tropospheric moisture retrievals, especially for upper tropospheric moisture. This study shows the advantage of using IR absorption bands 4.5, 6.7, 7.3, 13.3, 13.6, 13.9, and 14.2 $\mu \mathrm{m}$, which are constructed at VIIRS spatial resolution $(750 \mathrm{~m})$ using a data fusion approach using both sounder (CrIS) and imager (VIIRS) measurements following the approach in Weisz et al. (2017). The positive impact of adding the constructed fusion spectral bands on TPW and UTH retrievals is demonstrated. The moisture retrievals are based on the MODIS MYD07 Collection 6.1 algorithm package. Evaluations of the resulting moisture products are performed through comparisons to the operational MODIS Collection 6.1 and VIIRS (VIIRS-only and VIIRS+NUCAPS) version 1.0 moisture products.

Improvements in VIIRS+CrIS products, enabled by addition of fusion radiances, over the VIIRS-only and VIIRS+NUCAPS products are observed for TPW when quantitatively compared to the MYD08 products. In our 1month study for January 2017, the global mean of the TPW derived from the VIIRS+CrIS fusion radiances is $0.2 \mathrm{~mm}$ higher with a scatter of $1.4 \mathrm{~mm}$ when compared to the 
(a)

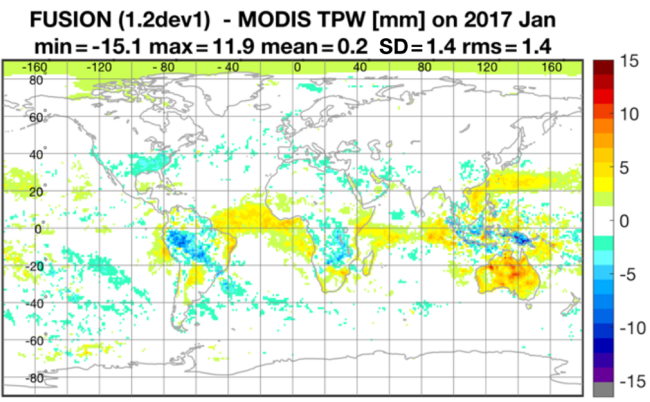

(c)

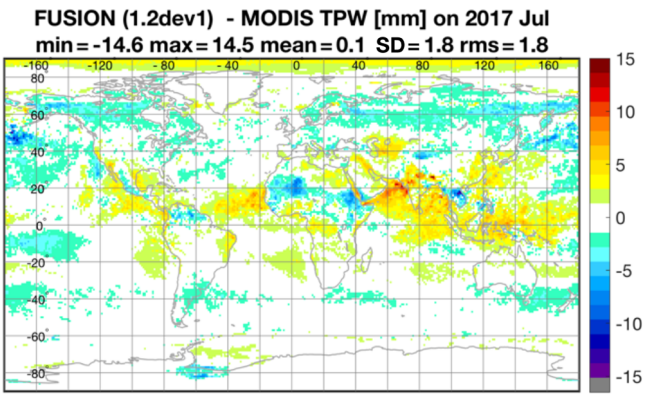

(b)

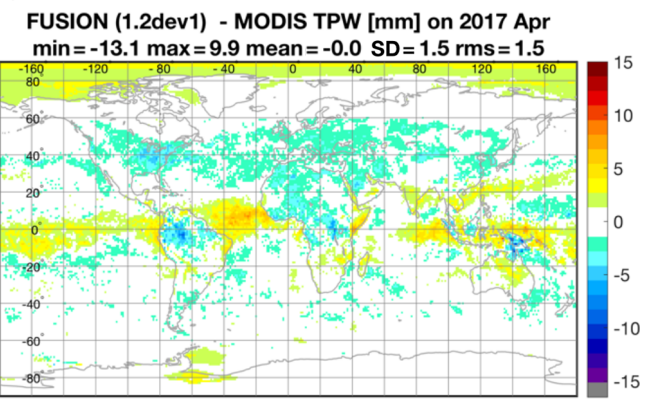

(d)

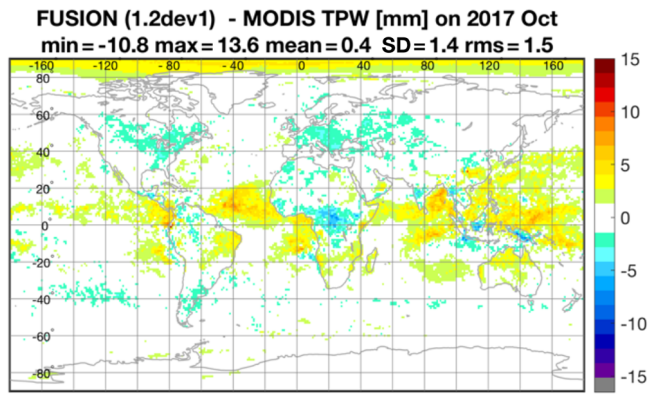

Figure 9. Geographical distribution of TPW (mm) differences between the VIIRS+CrIS fusion and the MODIS MYD08_M3 Collection 6.1 products for (a) January, (b) April, (c) July, and (d) October 2017 representing the four seasons. Minimum (min), maximum (max), mean, standard deviation (SD), and root mean square (rms) differences are shown in the subtitles.

(a)

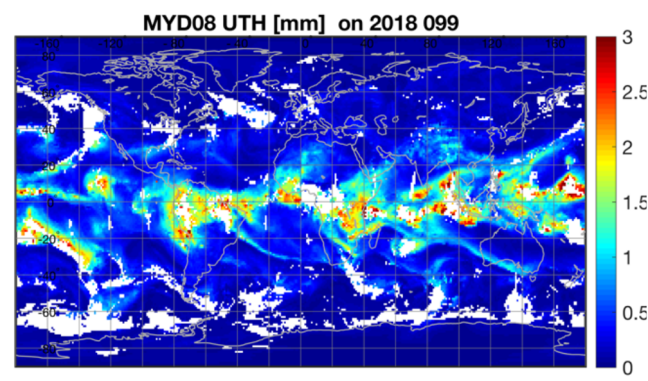

(b)

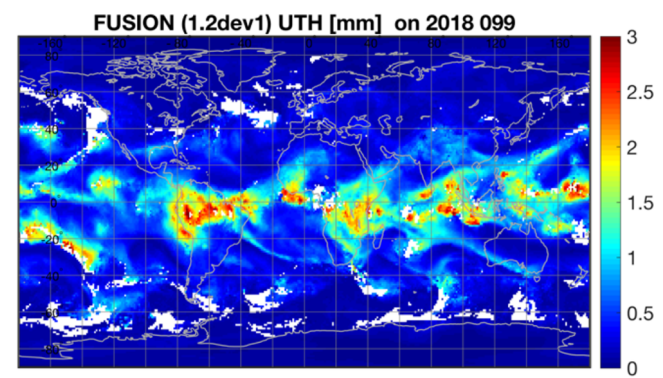

(c)

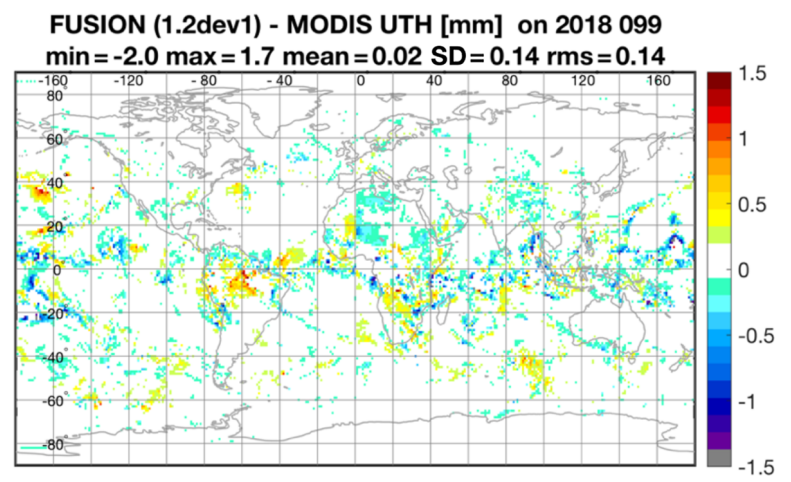

Figure 10. Geographical distribution of UTH (mm) results derived from the MODIS Collection 6.1 (a) VIIRS+CrIS fusion (b), and their differences (c) for 9 April 2018. The minimum (min), maximum (max), mean, standard deviation (SD), and root mean square (rms) differences are shown in the subtitles. 

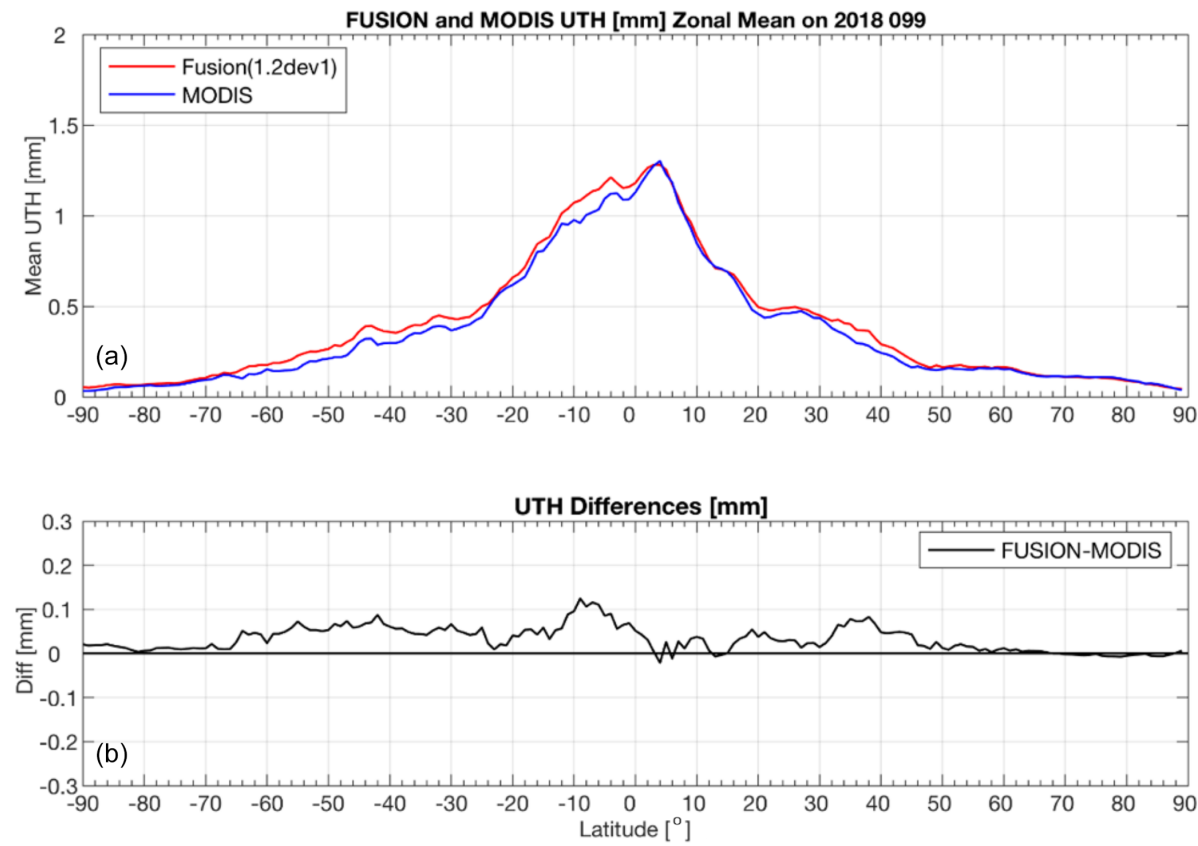

Figure 11. Panel (a) latitudinal distribution of UTH (mm) results for MODIS and VIIRS+CrIS fusion-derived from the same 9 April 2018 data shown in Fig. 10. Panel (b) illustrates the corresponding differences. The number of observations found in each $1^{\circ}$ latitude bins is shown in Fig. 5c.

(a)

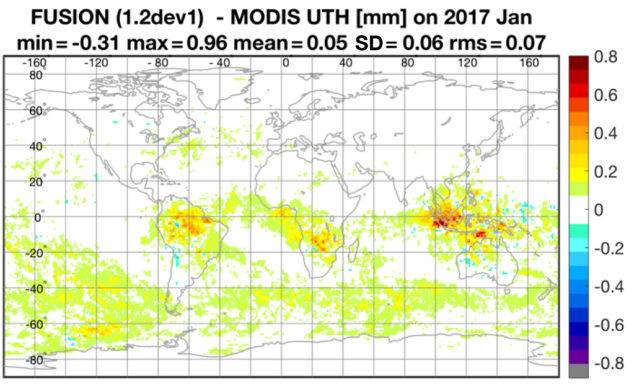

(c)

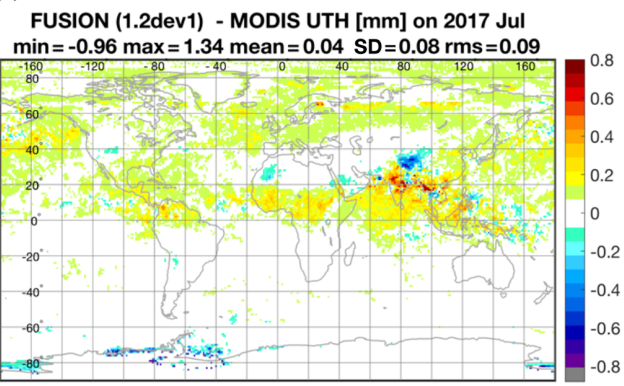

(b)

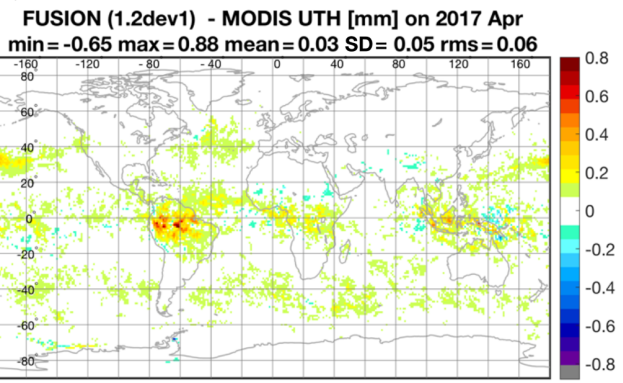

(d)

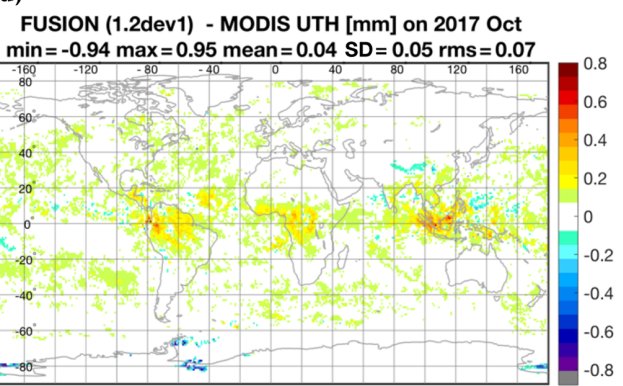

Figure 12. Same as Fig. 9 but for UTH.

MYD08 TPW; without the fusion radiances (VIIRS-only product), the mean is $1.1 \mathrm{~mm}$ too high with a scatter of $2.7 \mathrm{~mm}$ with most of the overestimation occurring in the tropics. The VIIRS+CrIS fusion TPW also demonstrates improvement over the VIIRS+NUCAPS TPW (with $0.3 \mathrm{~mm}$ mean and $2.0 \mathrm{~mm}$ scatter with respect to the MYD08 product). Similar TPW results are also found for 1 month in each season of 2017. VIIRS+CrIS UTH, now possible with the addition of the fusion radiances, is found to be within $10 \%$ of the MYD08 UTH in mean and scatter for the same 4 months. 
The results in this study are limited to a VIIRS sensor scan angle of $50^{\circ}$ to minimize the impact of the CrIS swath being less than that of the imager. These findings are limited in scope but clearly demonstrate the potential in the use of the fusion IR absorption spectral bands in generating moisture products and continuing the moisture record from MODIS and the previous generations of polar-orbiting satellite sensors. In future work, we plan to extend this evaluation to longer time periods, undertake a global comparison of VIIRS+CrIS fusion moisture products with ground-based measurements (Bedka et al., 2010; Roman et al., 2016), and possibly replace the operational VIIRS+NUCAPS moisture products with the VIIRS+CrIS fusion-derived moisture products.

Code and data availability. The codes in the present work are available from the corresponding author upon request. The VIIRS/SNPP Cloud Mask, fusion (FUSRAD), and water vapor (WATVP) products and the level-3 MODIS 15 MYD08 products used in this study can be obtained from the NASA Level-1 and Atmosphere Archive and Distribution System (LAADS) Distributed Active Archive Center (DAAC), Goddard Space Flight Center, USA (Ackerman et al., 2019, https: //doi.org/10.5067/VIIRS/CLDMSK_L2_VIIRS_SNPP.001; Baum et al., 2019a, https://doi.org/10.5067/VIIRS/FSNRAD_L2_VIIRS_ CRIS_SNPP.001; Borbas et al., 2019c, https://doi.org/10.5067/ VIIRS/WATVP_L2_VIIRS_SNPP.001; Borbas et al., 2019d, https: //doi.org/10.5067/VIIRS/WATVP_M3_VIIRS_SNPP.001; Platnick et al., 2017a, http://dx.doi.org/10.5067/MODIS/MYD08_D3.061; Platnick et al., 2017b, http://dx.doi.org/10.5067/MODIS/MYD08_ M3.061).

Author contributions. EEB conceived and designed the TPW regression method, conducted the impact study, and performed the analyses. CM performed the fusion radiance validation in Sect. 2 . WPM and BAB made critical suggestions regarding the design of the study and significant improvements to the manuscript. EW provided expertise on the use of fusion products.

Competing interests. The authors declare that they have no conflict of interest.

Acknowledgements. We are grateful for the encouragement and support of Hal Maring (NASA Headquarters, Washington, DC). The fusion data are generated by A-SIPS at University of Wisconsin Madison and sent to LAADS for public distribution. The writing of this paper benefited from discussions with our colleague Richard Frey through his insight on the VIIRS cloud mask. We thank Pascal Brunel (Météo-France) for providing the spectrally shifted MODIS coefficients for RTTOV, and Geoff Cureton and Ethan Nelson for their processing efforts at the A-SIPS.
Financial support. This research has been supported by the NASA (grant no. 80NSSC18K0816).

Review statement. This paper was edited by Domenico Cimini and reviewed by two anonymous referees.

\section{References}

Ackerman, S., Frey, R., Holtz, R., and Dutcher, S: VIIRS/SNPP Cloud Mask and Spectral Test Results 6-min L2 Swath 750m, Version-1, NASA Level1 and Atmosphere Archive \& Distribution System (LAADS) Distributed Active Archive Center (DAAC), Goddard Space Flight Center, USA, https://doi.org/10.5067/VIIRS/CLDMSK_L2_VIIRS_SNPP.001, 2019.

Baum, B. A., Weisz, E., and Menzel, W. P.: SNPP VIIRS+CrIS Fusion L2 Product, NASA MODIS Adaptive Processing System, Goddard Space Flight Center, USA, https://doi.org/10.5067/ VIIRS/FSNRAD_L2_VIIRS_CRIS_SNPP.001, 2019a.

Baum, B. A., Menzel, W. P., and Weisz E.: Fusion of CrIS and VIIRS data to construct infrared (IR) absorption band radiances for VIIRS, Algorithm Theoretical Basis Document, V1.0, Cooperative Institute of Meteorological Satellite Studies, University of Wisconsin-Madison, available at: https: //ladsweb.modaps.eosdis.nasa.gov/missions-and-measurements/ viirs/VIIRSCrISFusionATBDv1.1.pdf (last access: 22 January 2021), 2019b.

Bedka S., Knuteson, R., Revercomb, H., Tobin, D., and Turner, D.: An assessment of the absolute accuracy of the Atmospheric Infrared Sounder v5 precipitable water vapor product at tropical, midlatitude, and arctic ground-truth sites: September 2002 through August 2008, J. Geophys. Res.-Atmos., 117, D17310, https://doi.org/10.1029/2009JD013139, 2010.

Bentley, J. L.: Multidimensional binary search trees used for associative searching, Commun. ACM, 18, 509-517, 1975.

Borbas, E., Seemann, S. W., Huang, H.-L., Li, J., and Menzel, W. P.: Global profile training database for satellite regression retrievals with estimates of skin temperature and emissivity, Proc. of the Int. ATOVS Study Conference-XIV, Beijing, China, 25-31 May 2005, 763-770, 2005.

Borbas, E., Seemann, S. W., Kern, A., Moy, L., Li, J., Gumley, L., and Menzel W.P.: MODIS Atmospheric Profile Retrieval - ATBD, Collection 6, Products: 07_L2, Cooperative Institute of Meteorological Satellite Studies, University of WisconsinMadison, available at: https://atmosphere-imager.gsfc.nasa.gov/ sites/default/files/ModAtmo/MOD07_atbd_v7_April2011_0.pdf (last access: 23 January 2021), 2011.

Borbas, E. E., Seemann, S. W., Li, Z., Li, J., Kern, A., and Menzel, W. P.: MODIS Atmosphere Profiles Product (07_L2) (Aqua), NASA MODIS Adaptive Processing System, Goddard Space Flight Center, https://doi.org/10.5067/MODIS/MYD07_L2.061, 2017.

Borbas, E. E., Hulley, G., Feltz, M., Knuteson, R., and Hook, S.: The Combined ASTER MODIS Emissivity over Land (CAMEL) Part 1: Methodology and High Spectral Resolution Application, Remote Sens., 10, 643, https://doi.org/10.3390/rs10040643, 2018. 
Borbas, E. E., Li, Z., Menzel, W. P., Dobor, L., and Rada, M.: VIIRS/Suomi-NPP Water Vapor Products; Algorithm Theoretical Basis Document, Cooperative Institute of Meteorological Satellite Studies, University of Wisconsin-Madison, available at: https://ladsweb. modaps.eosdis.nasa.gov/missions-and-measurements/viirs/ SNPPVIIRSWATVP001ATBD2019.pdf (last access: 23 January 2021), 2019a.

Borbas, E. E., Li, Z., Menzel, W. P., Dobor L., and Rada, M.: VIIRS/Suomi-NPP Water Vapor Products (WATVP) Users' Guide, Cooperative Institute of Meteorological Satellite Studies, University of Wisconsin-Madison, available at: https: //ladsweb.modaps.eosdis.nasa.gov/missions-and-measurements/ viirs/SNPPVIIRSWATVP001UserGuide2019.pdf (last access: 24 January 2021), 2019b.

Borbas, E. E., Li, Z., Menzel, W. P., Dobor, L., and Rada, M.: VIIRS/SNPP Level-2 Water Vapor Products, NASA MODIS Adaptive Processing System, Goddard Space Flight Center, USA, https://doi.org/10.5067/VIIRS/WATVP_L2_VIIRS_SNPP.001, 2019c.

Borbas, E. E., Li, Z., Menzel, W. P., Dobor, L., and Rada, M.: VIIRS/SNPP Level-3 Daily and Monthly Mean Water Vapor Products, NASA MODIS Adaptive Processing System, Goddard Space Flight Center, USA, https://doi.org/10.5067/VIIRS/WATVP_M3_VIIRS_SNPP.001, 2019d.

Gambacorta, A.: The NOAA Unique CrIS/ATMS Processing System (NUCAPS): Algorithm Theoretical Basis Document, NOAA Center for Weather and Climate Prediction (NCWCP), available at: https://pdfs.semanticscholar.org/ 8f02/7a6e31d08e299c4b79433ee4302b7a8d62cd.pdf (last access: 24 January 2021), 2013.

Hayden, C. M.: GOES-VAS simultaneous temperature-moisture retrieval algorithm, J. Appl. Meteor., 27, 705-733, 1988.

$\mathrm{Hu}$, L. and Brunsell, N. A.: A new perspective to assess the urban heat island through remotely sensed atmospheric profiles, Remote Sens. Environ., 158, 393-406, https://doi.org/10.1016/j.rse.2014.10.022, 2015.

Hulley, G., Malakar, N., and Freepartner, R.: Moderate Resolution Imaging Spectroradiometer (MODIS) Land Surface Temperature and Emissivity Product (MxD21) Algorithm Theoretical Basis Document, Collection-6, Jet Propulsion Laboratory, California Institute of Technology, available at: https://modis.gsfc.nasa.gov/ data/atbd/atbd_mod21.pdf (last access: 24 January 2021), 2017.

Li, J., Wolf, W., Menzel, W. P., Zhang, W., Huang, H.-L., and Achtor, T. H.: Global soundings of the atmosphere from ATOVS measurements: The algorithm and validation, J. Appl. Meteorol., 39, 1248-1268, 2000.

Li, Y., Baum, B. A., Heidinger, A. K., Menzel, W. P., and Weisz, E.: Improvement in cloud retrievals from VIIRS through the use of infrared absorption channels constructed from VIIRS+CrIS data fusion, Atmos. Meas. Tech., 13, 4035-4049, https://doi.org/10.5194/amt-13-4035-2020, 2020.

Moeller, C., Menzel, W. P., and Quinn, G.: Review of Terra MODIS thermal emissive band L1B Radiometric Performance, Proc. SPIE Optical Engineering + Applications, San Diego, USA, 26 September 2014, 92180T https://doi.org/10.1117/12.2062138, 2014.
Platnick, S., King, M., and Hubanks, P.: MODIS Atmosphere L3 Daily Product, NASA MODIS Adaptive Processing System, Goddard Space Flight Center, USA, http://dx.doi.org/10.5067/ MODIS/MYD08_D3.061,2017a.

Platnick, S., King, M., and Hubanks, P.: MODIS Atmosphere L3 Monthly Product, NASA MODIS Adaptive Processing System, Goddard Space Flight Center, USA, http://dx.doi.org/10.5067/ MODIS/MYD08_M3.061, 2017b.

Proud, S. R., Rasmussen, M. O., Fensholt, R., Sandholt, I., Shisanya, C., Mutero, W., Mbow, C., and Anyamba, A.: Improving the SMAC atmospheric correction code by analysis of Meteosat Second Generation NDVI and surface reflectance data, Remote Sens. Environ., 114, 1687-1698, https://doi.org/10.1016/j.rse.2010.02.020, 2010.

Roman, J., Knuteson, R., August, T., Hultberg, T., Ackerman, S., and Revercomb, H.: A global assessment of NASA AIRS v6 and EUMETSAT IASI v6 precipitable water vapor using groundbased GPS SuomiNet stations, J. Geophys. Res.-Atmos., 121, 8925-8948, https://doi.org/10.1002/2016JD024806, 2016.

Saha, S., Moorthi, S., Pan, H., Wu, X., and Wang, J.: The NCEP Climate Forecast System Reanalysis, B. Am. Meteorol. Soc., 91, 1015-1057, https://doi.org/10.1175/2010BAMS3001.1, 2010.

Saunders, R., Hocking, J., Turner, E., Rayer, P., Rundle, D., Brunel, P., Vidot, J., Roquet, P., Matricardi, M., Geer, A., Bormann, N., and Lupu, C.: An update on the RTTOV fast radiative transfer model (currently at version 12), Geosci. Model Dev., 11, 27172737, https://doi.org/10.5194/gmd-11-2717-2018, 2018.

Seemann, S. W., Li, J., Menzel, W. P., and Gumley, L. E.: Operational retrieval of atmospheric temperature, moisture, and ozone from MODIS infrared radiances, J. Appl. Meteor., 42, 10721091, 2003.

Seemann, S. W., Borbas, E. E., Knuteson, R. O., Stephenson, G. R., and Huang, H.-L.: Development of a global infrared emissivity database for application to clear sky sounding retrievals from multi-spectral satellite radiances measurements, J. Appl. Meteorol. Clim., 47, 108-123, 2008.

Smith, W. L. and Woolf, H. M.: A Linear Simultaneous Solution for Temperature and Absorbing Constituent Profiles from Radiance Spectra, Technical Proceedings of the Fourth International TOVS Study Conference held in Igls, Austria, 16-22 March 1988, edited by: Menzel, W. P., 330-347, 1988.

Smith, W. L., Weisz, E., Kireev, S., Zhou, D., Li, Z., and Borbas, E.: Dual-regression retrieval algorithm for real-time processing of satellite ultraspectral radiances, J. Appl. Meteorol. Clim., 51, 1455-1476, 2012.

Wan, Z.: New refinements and validation of the MODIS LandSurface Temperature/Emissivity products, Remote Sens. Environ., 112, 59-74, https://doi.org/10.1016/j.rse.2006.06.026, 2010.

Weisz, E., Smith Sr, W. L., and Smith, N.: Advances in simultaneous atmospheric profile and cloud parameter regression based retrieval from high spectral resolution radiance measurements, J. Geophys. Res.-Atmos., 118, 6433-6443, 2013.

Weisz, E., Baum, B. A., and Menzel, W. P.: Fusion of Satellite-Based Imager and Sounder Data to Construct Supplementary High Spatial Resolution Narrowband IR Radiances, J. Appl. Remote Sens., 11, 036022, https://doi.org/10.1117/1.JRS.11.036022, 2017. 